\title{
57
}

\section{The rise of the Lean Service Provider}

\author{
Keith WILLETTS, BT - Network Management Forum, UK
}

Global competition is making significant impacts on pricing for all communications services with consequent downward pressure on operating costs. At the same time capital and current account investment to develop new services and rebuild infrastructures for Broadband, multimedia services etc. is accelerating. This financial squeeze is causing all service providers: carriers, local operators, value added or large corporate communications divisions to seriously examine the way they do business.

The central theme of the talk will be the emergence around the world of the "lean operator" as new entrants into the marketplace with highly automated process structures and highly manageable networks emerge. Established players are also rapidly undergoing right-sizing and re-engineering programs to match new competitors. Issues such as end-to-end process automation, dealing with legacy systems and transformation of the network infrastructure (especially access networks) will be addressed.

The talk will use examples of other industries such as the deregulated airline industry and the emergence of 'lean production' by Japanese companies in the 1980's to help understand the profound restructuring that is occurring world-wide in the communications sector. A single key message will be that the established players need to change the way they operate rapidly or they will go under. Survivors will be those companies that simultaneously achieve major reductions in operating cost and major advances in customer service. This is as true for end user departments who will be replaced by outsourcing or managed services as it is the mainstream providers who will be eclipsed by lower cost, higher quality new entrants. 